\title{
Socially Optimal Electric Driving Range of Plug-in Hybrid Electric Vehicles
}

\author{
Eleftheria Kontou ${ }^{\mathrm{a}}$, Yafeng Yin ${ }^{\mathrm{a}}{ }^{1}$ and Zhenhong Lin ${ }^{\mathrm{b}}$ \\ ${ }^{a}$ Department of Civil and Coastal Engineering, University of Florida, Gainesville, Florida 32611 \\ bak Ridge National Laboratory, Knoxville, Tennessee 37932
}

\begin{abstract}
This study determines the optimal electric driving range of plug-in hybrid electric vehicles (PHEVs) that minimizes the daily cost borne by the society when using this technology. An optimization framework is developed and applied to datasets representing the US market. Results indicate that the optimal range is 16 miles with an average social cost of $\$ 3.19$ per day when exclusively charging at home, compared to $\$ 3.27$ per day of driving a conventional vehicle. The optimal range is found to be sensitive to the cost of battery packs and the price of gasoline. When workplace charging is available, the optimal electric driving range surprisingly increases from 16 to 22 miles, as larger batteries would allow drivers to better take advantage of the charging opportunities to achieve longer electrified travel distances, yielding social cost savings. If workplace charging is available, the optimal density is to deploy a workplace charger for every 3.66 vehicles. Moreover, the diversification of the battery size, i.e., introducing a pair and triple of electric driving ranges to the market, could further decrease the average societal cost per PHEV by $7.45 \%$ and $11.5 \%$ respectively.
\end{abstract}

Keywords: plug-in hybrid electric vehicle (PHEV); optimal all-electric driving range; minimum social cost; recharging opportunities

\section{Introduction}

\footnotetext{
${ }^{1}$ Corresponding Author. Email: yafeng@ufl.edu; Tel: 1-352-3929537
} 
Plug-in hybrid electric vehicles (PHEVs) offer promise to reduce the dependency on oil and mitigate traffic emissions. The most attractive characteristic of PHEVs is that they can be deployed immediately in the marketplace without building infrastructure to support their operations (National Research Council, 2010). Moreover, the PHEV market is not constrained by the range-anxiety barrier of battery electric vehicles (e.g. Lin, 2014).

PHEVs in a series configuration typically operate in either of two modes: the chargedepleting mode using electrical power and consuming no gasoline and the charge-sustaining mode consuming only gasoline (blended-mode PHEVs, which consume electricity and gasoline simultaneously, will not be examined in this study). The vehicle starts up operating in the charge-depleting mode, until its battery reaches a threshold state of charge where the electric range is exhausted. Then, it switches to the charge-sustaining mode (Markel et al., 2009). The electric driving range is a critical parameter for designing a PHEV. In the U.S. market, the majority of PHEVs that operate in a series configuration cover an electric driving range of approximately 30 to 38 miles, depending on driving in an urban or a highway environment (Department of Energy, 2014a). The U.S. Advanced Battery Consortium has proposed two sizes of battery: a 10-mile range and a 40-mile range (Pesaran et al., 2007). The criteria for determining the ranges include (a) battery pack cost, volume, weight, life and efficiency, (b) charge power and cycles, (c) energy for charge-sustaining operations and (d) battery concerns such as operating temperature and voltage (Pesaran et al., 2007). The Energy Policy Act of 1992 and the National Highway Traffic Safety Administration have set the minimum driving range; the final rule effective in 1999 allowed a minimum driving range of 7.5 miles on the EPA urban cycles and 10.2 miles on the EPA highway cycle for dual fueled electric vehicles (Department of Energy, 2014b). It is crucial to define the optimal electric driving range considering the developments of technologies, infrastructure and policies. Non-optimal driving ranges, if adopted, might hinder the success of the PHEV deployment and mislead relevant policy makings, resulting in greater societal costs (Lin, 2014).

This study focuses on determining optimal electric driving ranges of PHEVs in a series configuration to minimize the societal cost, which includes the cost internal and external to the users. More specifically, the former consists of the battery and daily operating costs while the latter is primarily environmental/emissions cost. Moreover, the paper aims at answering the research questions whether the government should deploy workplace chargers to further minimize the social cost, and if so, what is the optimal density of chargers to deploy.

Quite a few studies in the literature have investigated optimal driving ranges of electric vehicles. For example, from the users' perspective, Lin (2012 and 2014) minimized the internal costs of battery and vehicle operations to define the optimal electric driving range for PHEVs and battery electric vehicles (BEVs) respectively. Shiau et al. (2010) optimized the PHEV design while allocating PHEVs, hybrid electric vehicles and conventional vehicles to the driving population for minimum petroleum consumption, greenhouse gas (GHG) emissions and life cycle cost. Traut et al. (2011) optimized the design of the previously mentioned mix of vehicles in order to minimize only GHG emissions by investigating workplace charging scenarios as well. Another contribution by Smith et al. (2011) finds the mimum battery capacity for a PHEV that meets the needs of urban commuters and their daily duty cycle. Another stream of studies have investigated the role of charging PHEVs within day on reducing gasoline consumption, e.g., Dong and Lin (2012), Zhang et al. (2011) and Dong et al. (2014). More recently, Peterson and Michalek (2013) assessed the cost effectiveness of increased battery size and deploying nondomestic charging infrastructure for PHEVs to reduce gasoline consumption. 
Compared to previous studies such as Lin (2012 and 2014), this paper investigates the optimal electric driving range of PHEVs from a societal perspective, taking into account the environmental impacts of PHEVs, including the external cost of emissions during the manufacturing of batteries and the operations of the vehicles. The paper differs from other relevant studies such as Shiau et al. (2010) and Traut et al. (2011) by, e.g., examining how the deployment of workplace charging infrastructure affects the optimal electric driving range. Our framework allows for direct comparison of the effects of different policies, such as deployment of workplace charging or the diversification of battery sizes on the cost borne by the society in order to access their effectiveness, under the scenario of universal adoption of PHEVs.

Our base modeling results confirm previous research findings (e.g., Michalek et al. 2011) where smaller batteries were found to offer larger social benefits per dollar. The diversification case yields results that are in general accordance with the USABC recommendations for PHEVs electric ranges of 10 and 40 miles (Pesaran et al. 2007). However, the recharging case results differ from the existing literature where a small PHEV battery (approximately 7-mile driving range) was suggested to be optimal for minimizing social costs (Shiau et al. 2009).

The remainder of this paper is organized in six sections. Section 2 presents a basic modeling framework for optimizing electric driving range of PHEVs. Section 3 describes the data used in this study. Section 4 presents the results in the context of the U.S. market, followed by a sensitivity analysis in Section 5. Section 6 further extends the base model to consider the deployment of workplace chargers and the diversification of the battery size. The last section summarizes and concludes the paper.

\section{Electric Driving Range Optimization Framework}

This section presents a modeling framework to optimize the electric driving range of PHEVs. The framework aims at minimizing the relevant social cost of using the technology, which consists of three distinctive components: the first one is an internal user cost, accounting for the capital cost of battery packs and the energy cost of operating a PHEV; the second is an external environmental cost, incorporating the cost of greenhouse gases (GHG) emissions from the manufacturing process of battery packs and the operation process of the vehicle; and the third component represents the expenditure of installing workplace chargers. Note that we only consider cost items that are dependent on the electric driving range. Moreover, although some cost items may be perceived differently by different users, (Stephens 2013), we do not account for such heterogeneity in the paper.

The optimization model is written as follows:

$$
\begin{array}{ll} 
& \min C(r)=\sum_{j}\left(C_{u_{j}}(r)+C_{e_{j}}(r)\right)+C_{g} \\
\text { s.t. } & 0 \leq r \leq r_{u}
\end{array}
$$

where the decision variable $r$ is the electric driving range in miles; $C(r)$ is the daily social cost related to the electric driving range; $C_{u_{j}}(r)$ is the daily cost internal to user $j, C_{e_{j}}(r)$ is the daily cost external to user $j$, i.e., the environmental cost and $C_{g}$ is the expenditure associated with the installation of workplace chargers. Constraint (2) dictates the lower and upper bound of the electric driving range, which is 0 and $r_{u}$ respectively. 
Below we discuss the three cost components in detail. For simplicity, we drop $j$, which pertains to each individual user, from related variables.

\subsection{Internal user cost}

As shown in Eq.(3), the user cost consists of two major components: the cost of battery packs and the operating cost, both in $\$ /$ day.

$$
C_{u}(r)=C_{b}(r)+C_{o}(r)
$$

where $C_{b}(r)$ is the cost of battery packs and $C_{o}(r)$ is the cost of consuming electricity and gasoline in operating a PHEV. Note that the cost of the other parts of the vehicle is not taken into account as it is assumed to largely independent of the decision variable $r$, the electric driving range.

The cost of battery packs is a function of electric driving range $r$ as expressed in Eq.(4). The equation is adopted from Lin (2014) with minor modification.

$$
C_{b}(r)=r \cdot n_{e}(r) \cdot k \cdot B_{a}(r) / h_{b}
$$

where $n_{e}(r)$ is the onboard electricity use rate in the charge-depleting mode in $\mathrm{kWh} / \mathrm{mile} ; k$ is the markup factor that casts the marketing and distribution costs of the battery packs; $B_{a}(r)$ is the amortized battery cost in $\$ / \mathrm{kWh} /$ day and $h_{b}$ is the battery utilization factor, i.e., the ratio of usable capacity over the total battery capacity. As the total battery capacity increases, the size of battery packs increases and the PHEV can cover a greater electric driving distance $r$. However, the electricity onboard usage rate will increase with $r$ due to the additional weight of the battery packs added to the vehicle. The amortized battery pack cost is calculated as follows:

$$
B_{a}(r)=\frac{B(r)}{a} \cdot C R F
$$

where $C R F=\left(\frac{i(1+i)^{n}}{(1+i)^{n}-1}\right)$ is the capital recovery factor representing the ratio of a constant annuity to the present value of receiving that annuity over $n$ years; $i$ is the discount rate; $a$ is the number of driving days per year; and $B(r)$ is the battery pack cost in $\$ / \mathrm{kWh}$, which is expected to decrease as the battery capacity increases due to the economy of scale assumption (Lin, 2014). The number of years $n$ into the future depends on the life spans of the battery and the vehicle. For the latter, driving a greater distance every day leads to a shorter life span of the vehicle (Pearre et al., 2011). Assuming that the designed mileage of a vehicle to be $m$, we have $n=$ $\min \left(n_{u},\left(\frac{m}{d}\right) / a\right)$, where $d$ is the daily driving distance of a user and $n_{u}$ the battery life span.

Modified from the one in Hendrickson et al. (2010), the second addend of the user cost represents the expense of consuming electricity and gasoline when a user operates the vehicle each day, as shown below:

$$
C_{o}(r)=\left(d_{e}(r) \cdot e \cdot n_{e}(r) \cdot\left(\frac{1}{n_{c}}\right)\right)+\left(d_{g}(r) \cdot \frac{g}{n_{g}(r)}\right)
$$

where $e$ is the price of electricity in $\$ / \mathrm{kWh} ; n_{c}$ is the battery charging efficiency, i.e., the amount of electricity consumed onboard per unit of electricity transferred from the grid (Lin, 2014); $g$ is the price of gasoline in \$/gallon and $n_{g}(r)$ is PHEV's gasoline fuel economy in mile per gallon when the vehicle operates in the charge-sustaining mode. The efficiency decreases as the electric driving range increases due to heavier battery packs. Let $d_{e}(r)$ and $d_{g}(r)$ represent the daily distance travelled in miles by a user using electricity in the charge-depleting mode and gasoline in the charge-sustaining mode respectively. Assuming home charging is available and each PHEV is fully charged in the morning, these distances are estimated as per Eqs.(7)-(8): 


$$
\begin{gathered}
d_{e}(r)=\min (r, d) \\
d_{g}(r)=\max (0, d-r)
\end{gathered}
$$

In Eqs.(7)-(8), $d$ is the distance that a particular user travels every day on average. Here we assume in the base case that there is scarce public charging infrastructure and PHEVs are exclusively charged at home. We note that based on results from Traut et al. (2013), home charging is not always an option to the U.S. households. Thus, Eq. (7) may overestimate the electrified distance while Eq. (8) may underestimate the fueled distance.

Another cost component associated with the maintenance of the PHEV engine can also be considered. The maintenance cost of a PHEV engine is related to the cycles of the chargingdischarging battery process and may depend on the electric driving range $r$, because the range determines the miles that will be covered in the charge-sustaining mode. However, due to the unavailability of empirical data to fit the relationship, we do not incorporate this cost component in our framework. Lastly, previous studies, while assessing the social costs of the hybrid vehicles, incorporated in the user cost specification registration fees, insurance costs, tolls and federal/state fuel excise taxes (Lipman \& Delucchi 2006). These costs are considered as transfers and thus are not incorporated in the study.

\subsection{Environmental cost}

The PHEV's external cost contains the costs of the GHG emissions from manufacturing the battery and operating the vehicle, as described in Eq.(9):

$$
C_{e}(r)=G_{m}(r)+G_{o}(r)
$$

where $G_{m}(r)$ is the emissions cost associated with the battery manufacturing process, and $G_{o}(r)$ casts the operation-related GHG emission cost. Both costs are in \$/day.

The emissions cost associated with the GHG battery manufacturing is presented in Eq.(10)

(Shiau et al., 2010).

$$
G_{m}(r)=\left(b_{c}(r) \cdot v_{b} \cdot k_{c} \cdot \frac{1}{a} \cdot C R F\right) \cdot S C C
$$

where $b_{c}(r)$ is the number of battery cells, depending on the battery size; $v_{b}$ is the battery pack manufacturing emissions, estimated in $\mathrm{kgCO}_{2}$-equivalent per $\mathrm{kWh} ; k_{c}$ is the energy capacity per battery cell in $\mathrm{kWh} /$ cell and $S C C$ is the social cost of GHG in $\$ / \mathrm{kgCO}_{2}$-equivalent for the base year of our analysis, which quantifies the "monetized damages associated with an incremental increase in carbon emissions in a given year" (Environmental Protection Agency, 2013).

The daily GHG emissions cost associated with operating the vehicle is estimated by Eq.(11), which is modified from what proposed in Shiau et al. (2009):

$$
G_{o}(r)=\left(d_{e}(r) \cdot v_{e} \cdot n_{e}(r) \cdot\left(\frac{1}{n_{c}}\right)+d_{g}(r) \cdot \frac{v_{g}}{n_{g}(r)}\right) \cdot S C C
$$

where $v_{e}$ is the average $\mathrm{kgCO}_{2}$-equivalent per $\mathrm{kWh}$ of electricity consumed in the chargedepleting mode while $v_{g}$ is the average $\mathrm{kgCO}_{2}$-equivalent per gallon of gasoline consumed in the charge-sustaining mode.

The environmental cost associated with the disposal or recycling of a battery at the end of its life cycle is another important component to consider. However, the reuse of PHEV batteries is not expected to be cost-effective in the near future, assuming that the battery prices continue to decrease (Neubauer and Pesaran, 2011). Moreover, the literature associated with reusing PHEVs' batteries is thin. Since empirical data are not available to support a driving-rangedependent disposal cost, we do not include this component in our analysis. Social costs related to 
accidents and congestion do not depend on the electric driving range of the PHEVs and, therefore, are not incorporated in this study. On the other hand, air pollution and health externalities could be potentially assessed with life-cycle scenario analysis (Delucchi 2000; Tessum et al. 2014).

\subsection{Charging infrastructure}

In addition to the driving range of PHEVs, the charging opportunities also play vital roles in determining the states of charge of PHEVs. In this paper, we consider the deployment of workplace chargers. The required capital investment can be approximately estimated by Eq.(12):

$$
C_{g}=c_{g} \cdot \frac{C R F_{m}}{a} \cdot v
$$

where $c_{g}$ is the cost of installing one charger in $\$ ; C R F_{m}$ is capital recovery factor associated with the life cycle of a charger, and $v$ is the total number of installed chargers. Note that our base model does not consider workplace charging, thus $C_{g}=0$. This cost component plays a critical role when we consider deploying workplace chargers in Section 6.1.

\section{Data}

The optimization framework is applied to the U.S. PHEV market with the data from recent studies that pertain to the market. Hereinafter, only lithium-ion batteries for PHEVs are considered. Lithium-ion battery technology has higher energy densities, making it more appropriate for PHEV operations (Samaras and Meisterling, 2008). However, storing sufficient electricity still requires bulky batteries (Pearre et al., 2011). For battery prices, we use the goals that the U.S. Advanced Battery Consortium (USABC) assumed to be achieved in the base year of 2020 (Pesaran et al., 2007). The relationship between the battery cost $B(r)$ and battery capacity is depicted at Fig. 1. The function that relates the cost with the electric driving range $r$ is $B(r)=450 r^{-0.292}$.

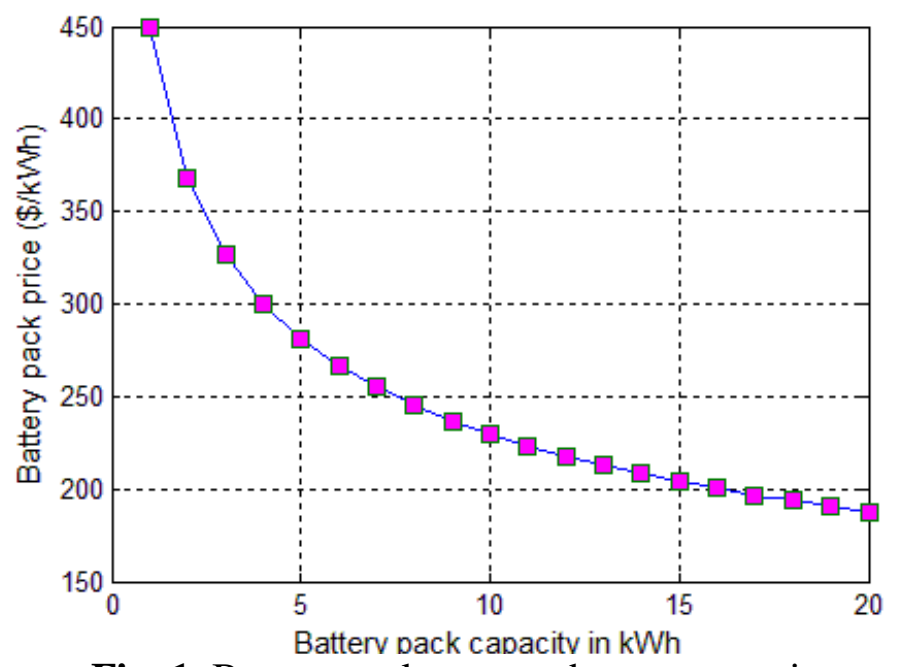

Fig. 1. Battery pack cost vs. battery capacity 
It is assumed that the battery utilization factor $h_{b}$ is $90 \%$; the battery charging efficiency $n_{c}$ is $90 \%$; the markup factor $k$ is $150 \%$ (Lin, 2014); the number of working/driving days per year are $a=250$; the designed mileage of a vehicle is $m=150,000$ miles and the battery life $n_{u}$ is 10 years (National Research Council, 2010). Moreover, the maximum electric driving range considered is a $r_{u}=100$ mile; the battery pack emissions in $\mathrm{kgCO}_{2}$-equivalent per $\mathrm{kWh}$ parameter is $v_{b}=0.0216$ and the energy capacity in battery cell is $k_{c}=120 \mathrm{kWh} /$ cell (Shiau and Michalek, 2011).

The data from 2009 U.S. National Household Travel Survey are utilized to define the daily driving distance of vehicles/drivers with a working purpose (U.S. Department of Transportation, 2009). In this study, we are particularly interested in the deployment of workplace charging and thus we do not look into trip chain datasets. For sample generation, data filtering is performed based on the following five criteria based on Lin (2014):

- Main driver of the household;

- The vehicle driven is a car, van, sport utility vehicle or a pickup truck;

- The main driver works from home at most 5 days per month;

- The vehicle is not carrying a commercial plate;

- The daily vehicle miles travelled (VMT) for working purposes do not exceed 200 miles.

Applying these criteria leads to a total sample of 40,161 entries. The average daily travel distance in the sample is 26.2 miles. We assume that the daily driving distance in the sample is representative and do not consider its day-to-day variations. We further assume that the travel pattern in the base year 2020 of our analysis is the same as that reflected in NHTS 2009 data. Note that FHWA (2013) reports a decrease in the total VMT in the U.S. from 2009 and we will examine the effects of potential changes to the daily commute VMT in Section 5.
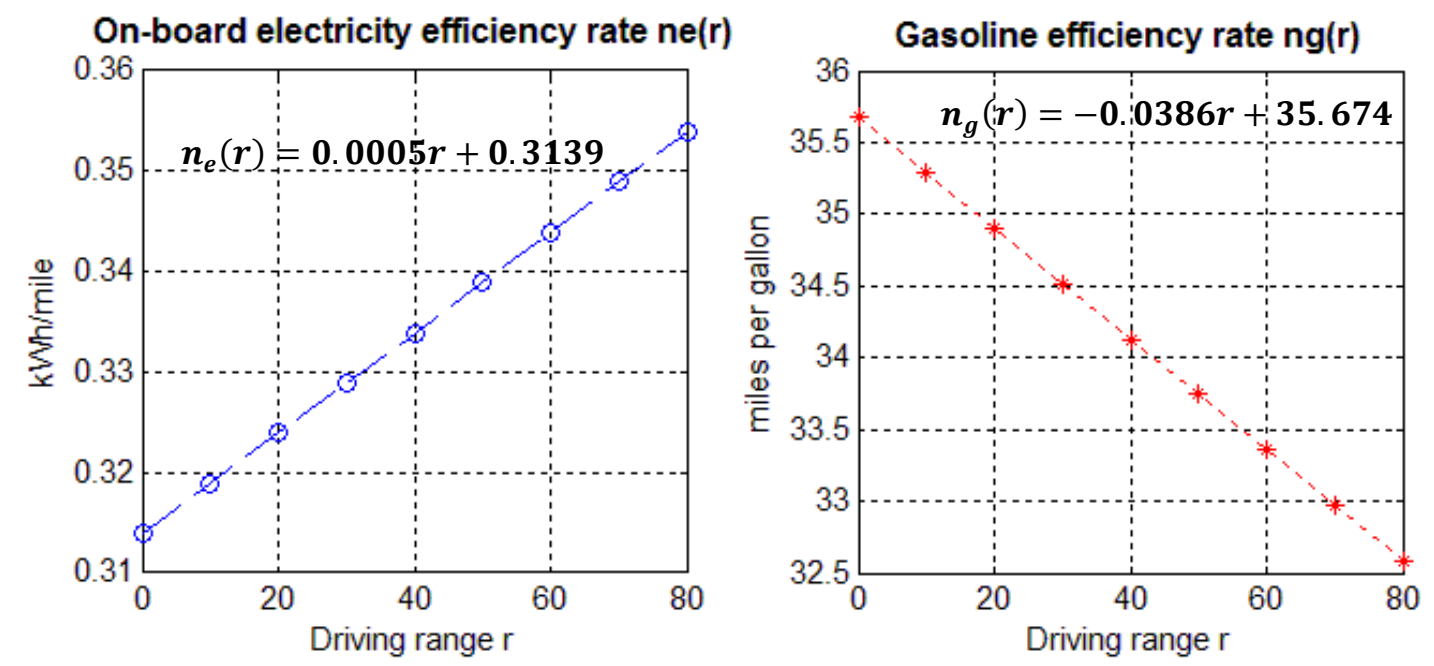

Fig. 2. Electricity and gasoline consumption rates

In order to define the relationship of the onboard electricity efficiency rate $n_{e}(r)$ and the gasoline efficiency rate $n_{g}(r)$ with the driving range $r$, we utilize the data from the literature, particularly those in Elgowainy et al. (2009). The resulting equations are presented in Fig. 2.

The price of electricity exclusively for the transportation sector is estimated using the data by state and provider during 1990-2012 (Energy Information Administration, 2013). It is 
assumed that the base price $e=0.11 \$ / \mathrm{kWh}$ for the base year 2020 while the gasoline price without tax $g=4.00$ \$/gallon.

The GHG emissions of PHEV in the charge-depleting mode are originated from the process of producing electricity. Based on Shiau et al. (2009), we have $v_{e}=0.730 \mathrm{~kg} \mathrm{CO}_{2}-$ $\mathrm{eq} / \mathrm{kWh}$. On the other hand, the GHG emissions in the charge-sustaining mode are estimated by summing the amounts of $\mathrm{CO}_{2}, \mathrm{CH}_{4}$ and $\mathrm{N}_{2} \mathrm{O}$ emissions of combusting a gallon of gasoline multiplied by their global warming potentials. The sum turns out to be $v_{g}=8.912 \mathrm{kgCO}_{2^{-}}$ equivalent/gallon (Energy Information Administration, 2013; Parry, 2007). In addition, the social cost of carbon (SCC), with a 3\% discount rate, is estimated to be $0.043 \$ / \mathrm{kgCO}_{2}$-equivalent (Environmental Protection Agency, 2013).

\section{Results}

We now discuss the results for the base case with home charging opportunity offered only. To provide a better picture of the composition of the daily social cost of operating a PHEV, Table 1 presents each cost component associated with a daily VMT of 26.2 miles for a selected number of designs of PHEV driving ranges. As previously noted, 26.2 miles is the average driving distance for working purposes in our samples.

Table 1 Cost Components for Daily VMT of 26.2 Miles

\begin{tabular}{|c|c|c|c|c|c|c|}
\hline & PHEV-10 & PHEV-20 & PHEV-30 & PHEV-40 & PHEV-50 & PHEV-60 \\
\hline Driving range $r$ (miles) & 10 & 20 & 30 & 40 & 50 & 60 \\
\hline Battery cost $C_{b}(r)$ & 0.52 & 0.86 & 1.16 & 1.44 & 1.71 & 1.97 \\
\hline User operating cost $C_{o}(r)$ (\$/day) & 1.92 & 1.10 & 1.02 & 1.05 & 1.07 & 1.10 \\
\hline $\begin{array}{l}\text { Operating emissions cost } G_{o}(r) \\
\text { (\$/day) }\end{array}$ & 0.25 & 0.24 & 0.29 & 0.30 & 0.31 & 0.31 \\
\hline $\begin{array}{l}\text { Battery manufacturing emissions } \\
\text { cost } G_{m}(r)(\$ / \text { day })\end{array}$ & 0.01 & 0.02 & 0.03 & 0.04 & 0.05 & 0.06 \\
\hline Social Cost $C(\boldsymbol{r})(\$ /$ day $)$ & 2.70 & 2.22 & 2.50 & 2.83 & 3.14 & 3.44 \\
\hline
\end{tabular}

It can be observed that two major cost components are the battery cost and the cost of consuming electricity and gasoline. Although the environmental cost is not a major component, it still contributes to approximately $10 \%$ of the social cost. Fig. 3 illustrates how each average cost component varies with respect to the electric driving range. Intuitively, the costs of battery and its manufacturing emissions increase with the driving range. A larger battery will also electrify longer travel distances and thus lead to a lower energy cost. This mechanism prevails such that the operating user cost decreases with the driving range. Interestingly, the operating emissions cost decreases and then increases with the driving range. This suggests that if the battery of the PHEV is unnecessarily too large, it could lead to greater emissions due to the worse fuel economy caused by the added vehicle weight. 

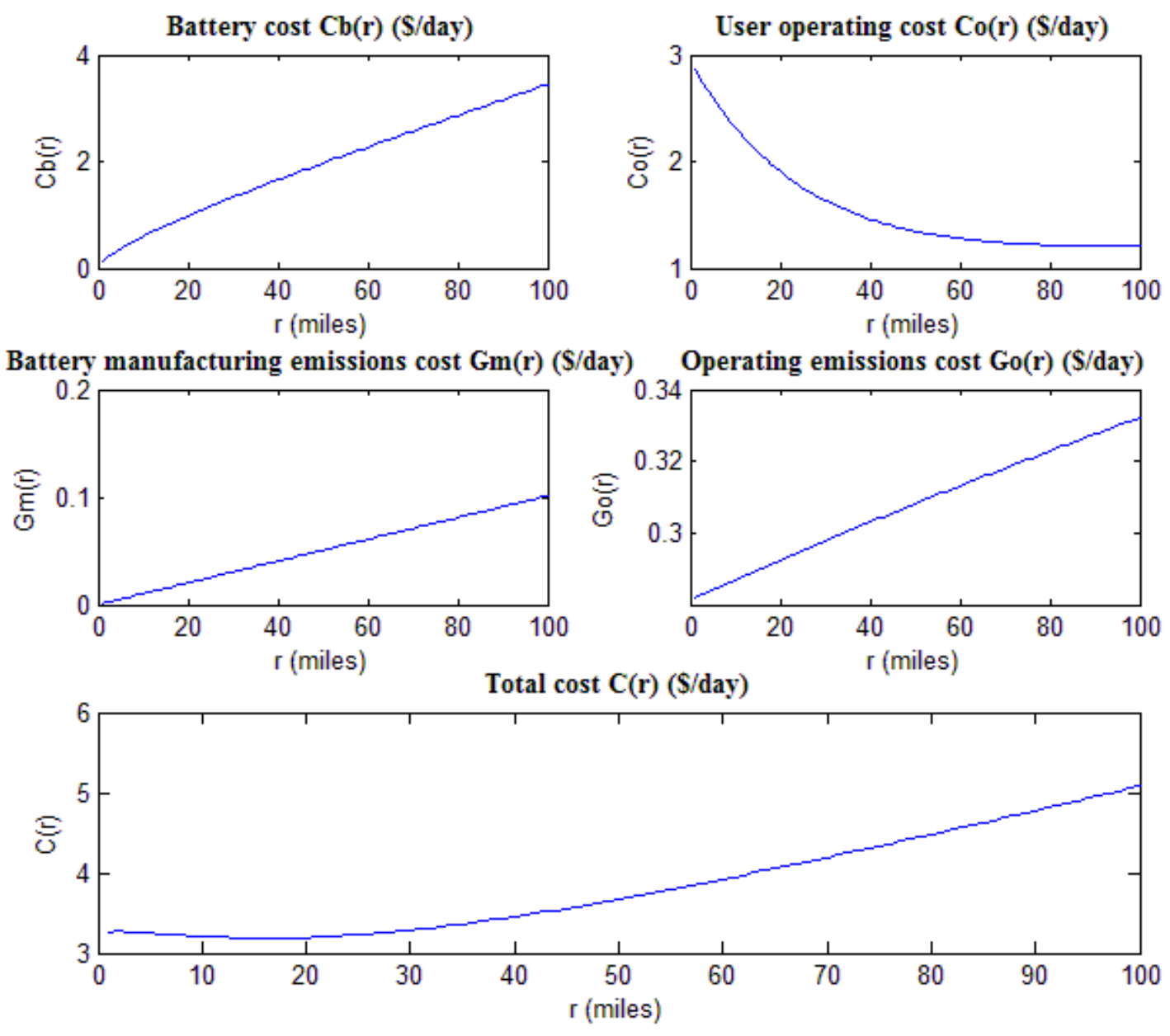

Fig. 3. Changes of cost components with respect to driving range (home-charging only)

The optimization model is solved by using the KNITRO solver (Waltz \& Plantenga 2009) in GAMS 23.3 (Rosenthal, 2004) and the resulting optimal electric driving range is 16 miles with the minimum daily societal cost of $\$ 3.19$ per PHEV. This suggests that, if prescribed for all consumers, the driving ranges of PHEVs (in a series configuration) in the market, i.e., 30-38 miles, are not socially optimal and yield higher social costs as compared with the optimal driving range of 16 miles. This is not surprising as those driving ranges are not designed from the social perspective; our -indicative results suggest that a lower driving range is more beneficial to the society. These results are largely consistent with the literature (e.g. Michalek et al. 2011 and Lin 2012), which suggested that PHEVs with smaller battery packs are more socially cost effective. On the other hand, this might discourage consumers from purchasing PHEVs, especially those living in rural areas, who may drive longer than 16 miles daily. In general, we should recognize the need to consider consumer heterogeneity and product diversification. Some PHEV consumers may be better off with the 30-38 miles of electric range, while others may be wise to choose a shorter electric range. The finding of an average optimal range means no criticism of long-range PHEV products, but only suggests a policy direction to encourage adoption of shortrange PHEVs, for societally cost-effective mitigation of GHG. Similar suggestion has been made 
in previous studies (Shiau et al. 2009), indicating that policymaking should consider promoting smaller capacity PHEVs. In fact, PHEVs with 10-25 mile electric range are already being offered in the market but those operate in blended mode, consuming both gasoline and electricity during the charge-depleting mode.

The flat area of the social cost curve between 13 and 20 miles in Fig. 3 implies that the social cost is not sensitive to the electric driving range within this interval. However, those driving ranges are all smaller than those currently available in the marketplace. It is also interesting to note the case when the electric driving range is approaching zero $(r \approx 0)$, where the vehicle is essentially a conventional one with gasoline efficiency being approximately 35 mpg. Compared to this case, a universal adoption of PHEVs with the optimal driving range of 16 miles reduces the average daily social cost by approximately $2.42 \%$.

\section{Sensitivity Analysis}

In this section, the validity of the indicative optimal driving range discussed above is examined against primary input parameters of the model, which are certainly subject to uncertainty. Table 2 presents optimistic and pessimistic variations or changes of these parameters considered in our sensitivity analyses. Fig. 4 shows how the optimal driving range changes with respect to those variations.

The optimal driving range is found to be most sensitive to the battery pack cost and the gasoline price. More specifically, it changes by $25.00 \%$ in response to a $10.00 \%$ change in the gasoline price, by $25.00 \%$ with respect to $10.00 \%$ change of the charging potential and by 0 $12.50 \%$ in response to every other factor. The optimal driving range is found to be elastic to the production source of the electricity that batteries are charged with, e.g., coal, natural gas or, particularly, nuclear power. The factors having the greatest impact on the value of the minimum societal cost are the gasoline - price and the discount rate, with a $10.00 \%$ increase of the first parameter resulting in 5\% increase of the cost and with a $2.00 \%$ increase of the second parameter resulting in $6.90 \%$ decrease of the cost. An increase or decrease of $1.00 \%$ in the VMT has little impact on the optimal driving range result.

Table 2 Baseline and Sensitivity Analysis Parameters

\begin{tabular}{|c|c|c|}
\hline & Baseline & Sensitivity Analysis \\
\hline $\begin{array}{l}\text { Battery cost probable estimates } \\
2020\end{array}$ & USABC for 2020 & $\begin{array}{l}\text { Optimistic: }-5.00 \% \text { change } \\
\text { Pessimistic: }+5.00 \% \text { change }\end{array}$ \\
\hline Charging potential $n_{c}$ & $n_{c}=90 \%$ & $\begin{array}{l}\text { Optimistic: }+10.00 \% \\
\text { Pessimistic: }-10.00 \%\end{array}$ \\
\hline Discount rate & $3 \%$ average & $\begin{array}{l}\text { Optimistic: } i=5.00 \% \\
\text { Pessimistic: } i=2.50 \%\end{array}$ \\
\hline Battery utilization $h_{b}$ & $h_{b}=90 \%$ & $\begin{array}{l}\text { Pessimistic: }-10.00 \% \\
\text { Optimistic: }+10.00 \%\end{array}$ \\
\hline Gasoline price & $g=\$ 4 /$ gallon & $\begin{array}{l}\text { Optimistic: }-10.00 \% \\
\text { Pessimistic: }+10.00 \%\end{array}$ \\
\hline Electricity price & $e=\$ 0.11 / k W h$ & $\begin{array}{l}\text { Optimistic: }-10.00 \% \\
\text { Pessimistic: }+10.00 \%\end{array}$ \\
\hline Markup factor $k$ & $k=150 \%$ & $\begin{array}{l}\text { Optimistic: }-10.00 \% \\
\text { Pessimistic: }+10.00 \%\end{array}$ \\
\hline Daily commute VMT & NHTS 2009 & $\pm 1.00 \%$ \\
\hline $\begin{array}{l}\text { Electricity GHG emissions } \\
\text { based on source of production }\end{array}$ & Coal: $0.73 \mathrm{kgCO} 2 \mathrm{eq} / \mathrm{kWh}$ & $\begin{array}{l}\text { Natural gas: } 0.47 \mathrm{~kg} \mathrm{CO} 2 \mathrm{eq} / \mathrm{kWh} \\
\text { Nuclear: } 0.066 \mathrm{kgCO} 2 \mathrm{eq} / \mathrm{kWh}\end{array}$ \\
\hline
\end{tabular}




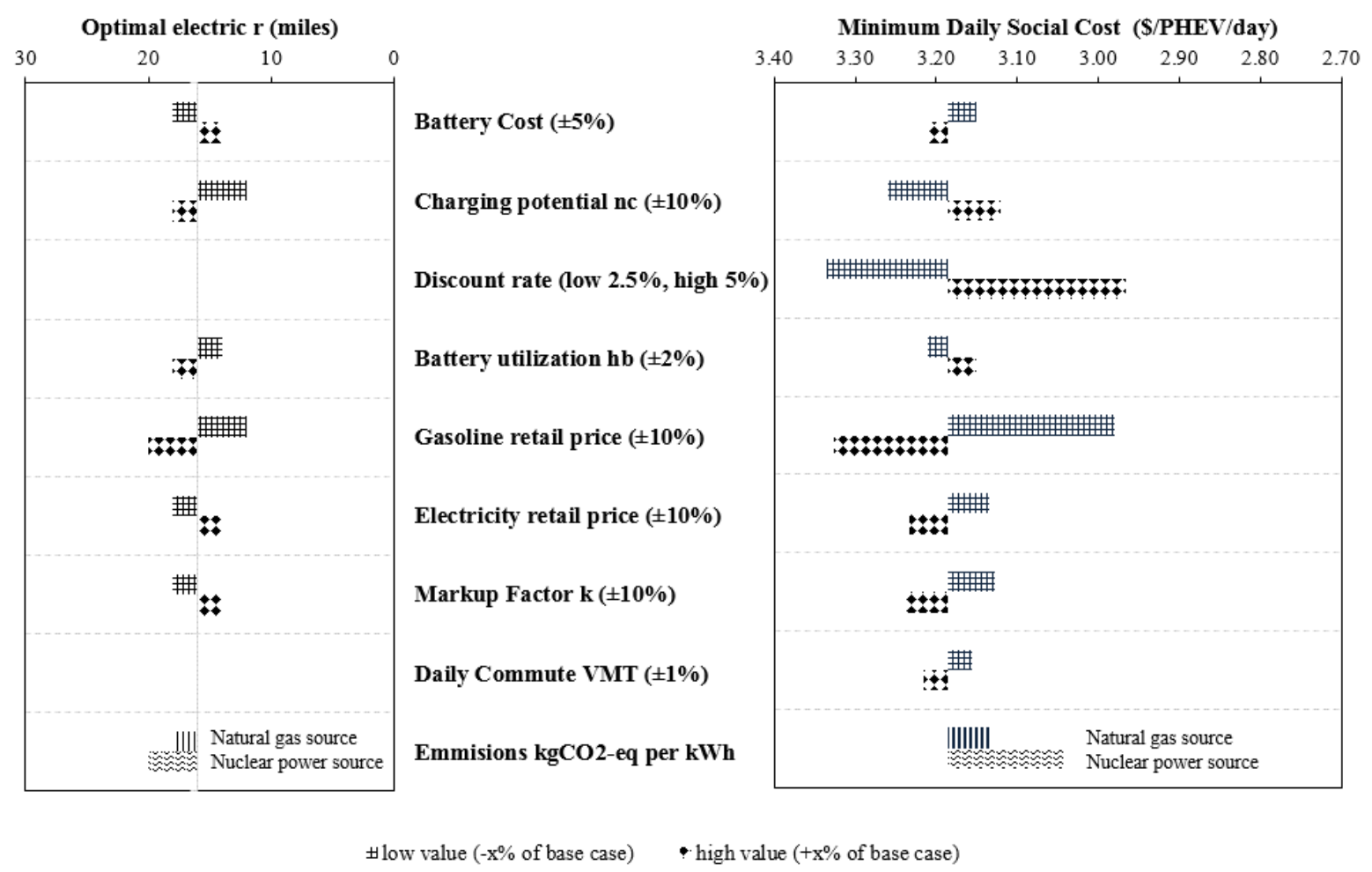

Fig. 4. Sensitivity of the optimal electric driving range and the minimum social cost

\section{Model Extensions}

\subsection{Deployment of workplace charging infrastructure}

We now extend our base model to consider the deployment of workplace charging infrastructure. We are interested in investigating whether the deployment can further reduce the societal cost of the PHEV usage; how many chargers need to be deployed and how the availability of workplace charging affects the optimal driving range.

The availability of workplace chargers primarily impacts the user operating cost $C_{o}(r)$ and the operating environmental cost $G_{o}(r)$. Both costs are expected to decrease if drivers recharge their PHEVs during the day. In our analysis, we assume that drivers follow a simple daily trip chain of home-to-work and work-to-home. For driver $j$, the one-way distance is $d_{j} / 2$, assuming that the driver chooses the same route both ways. Consequently, the state of charge of the PHEV battery at the destination of the first trip, i.e., workplace, is given as follows:

$$
s_{j}^{1}(r)=\max \left(r-\frac{d_{j}}{2}, 0\right)
$$

Given the dwell time $t$ at the work (in hours) and $P$ the charging power at the charging station (in $\mathrm{kW}$ ), the battery state of charge before heading home is calculated based on Eq.(14). 


$$
s_{j}^{2}\left(x_{j}, r\right)=\left\{\begin{array}{c}
s_{j}^{1}(r), \text { if } x_{j}=0 \\
\min \left(r, s_{j}^{1}(r)+\frac{P \cdot t}{n_{e}(r)}\right), \text { if } x_{j}=1
\end{array}\right.
$$

where $x_{j}$ is a binary variable, equal to 1 if the PHEV recharges at work and 0 otherwise. The electrified distance and the gasoline-fueled distance for the first trip can be estimated as follows:

$$
d_{e_{j}}{ }^{1}(r)=\min \left(r, \frac{d_{j}}{2}\right), d_{g_{j}}{ }^{1}(r)=\max \left(0, \frac{d_{j}}{2}-r\right)
$$

In this case, we assume that PHEVs are fully charged before leaving home for work.

Similarly, the distances for the work-to-home trip are calculated based on Eq.(16).

$$
d_{e_{j}}^{2}\left(x_{j}, r\right)=\min \left(s_{j}^{2}\left(x_{j}, r\right), \frac{d_{j}}{2}\right), d_{g_{j}}^{2}\left(x_{j}, r\right)=\max \left(0, \frac{d_{j}}{2}-s_{j}^{2}\left(x_{j}, r\right)\right)
$$

The total electrified and gasoline-fueled miles are the summations of the above, and are further used to estimate the operational costs associated with energy consumption and emissions. We denote the internal user cost and the external environmental cost as $C_{u_{j}}\left(r, x_{j}\right)$ and $C_{e_{j}}\left(r, x_{j}\right)$ respectively. The cost of installing chargers is given by Eq.(12), denoted as $C_{g}(v)$, where $v$ is the number of chargers to be deployed at the workplaces. Given the number of deployed chargers will be less than the number of PHEVs, we need to decide who will get to use those chargers. The modeling framework in this paper does not allow us to consider optimal locations of charging stations for PHEVs and describe the charging behaviors of drivers like previous studies such as He et al. (2013). Instead, we assume that the locations of workplace chargers are always optimal so that those who benefit the most from recharging will get to use them. In essence, it is assumed that the workplace chargers are optimally located to maximize the savings that drivers receive from recharging their vehicles.

With the above considerations, the extended optimization model is written as follows:

$$
\begin{gathered}
\quad \min C(r, v)=\sum_{j}\left(C_{u_{j}}\left(r, x_{j}^{*}\right)+C_{e_{j}}\left(r, x_{j}^{*}\right)\right)+C_{g}(v) \\
\text { s.t. } \quad 0 \leq r \leq r_{u} \\
\quad x^{*}=\operatorname{argmax}\left\{\sum_{j} \hat{C}_{u_{j}}\left(r, x_{j}\right) \mid \sum_{j} x_{j}=v, x_{j} \in\{0,1\}, \forall j\right\}
\end{gathered}
$$

where $\widehat{C}_{u_{j}}\left(r, x_{j}\right)=\left\{C_{u_{j}}(r, 1)-C_{u_{j}}(r, 0)\right\} x_{j}$, i.e., the cost saving if recharging at workplace for user $j$.

The above model is a bi-level mathematical programming model. The upper-level is to minimize the social cost by deciding the driving range and number of workplace chargers. The lower-level problem identifies drivers who will benefit the most from recharging their vehicles at workplaces. Note that in Eq. (18), $\sum_{j} x_{j}=v$ implies that a vehicle will occupy one charger for the day. Assuming one vehicle per charger may overestimate the number of chargers, since under most circumstances PHEVs will need only a partial day of charging. This constraint can be revised to reflect this.

We now solve the above model with the same data described previously and consider deploying Level-2 chargers, which offer charging at $240 \mathrm{~V}$ with a charging time ranging from 2.5 to 8 hours depending on the battery size of PHEVs (Yilmaz and Krein, 2013). The installation cost for a Level-2 charger varies from $\$ 1,000$ to $\$ 3,000$. In our study, we consider an 
investment cost of $c_{g}=\$ 1,852$ per charger (Yilmaz and Krein, 2013). The capital recovery factor of the charging infrastructure is assumed $C R F_{m}=0.12$, based on a $3 \%$ discount rate.

We use Fig.5 to demonstrate how the deployment of workplace chargers impacts the operating user and environmental costs. Specifically, the figure shows the scenarios of deploying $100,1,000$ and 20,000 chargers, as well as the optimal number of chargers, i.e., 10,958. Those scenarios are equivalent to assuming 1 charger per 401.61, 40.16, 2.08 and 3.66 vehicles respectively. It can be observed that deploying workplace chargers will further reduce the societal cost; the scale of this cost reduction depends on the charging density deployed. For example, when the government decides to deploy 1,000 chargers, the optimal driving range increases to 18 miles and the average daily societal cost drops to $\$ 3.18$ per PHEV. When the government can provide only 100 chargers, perhaps due to a limited budget, the optimal electric driving range remains a 16-mile and the societal cost is found to be $\$ 3.19$ per PHEV.

When deploying the optimal number of chargers, i.e., 10,958, which is equivalent to deploy a charger for every 3.66 vehicles, the societal cost decreases by $4.54 \%$ ( $\$ 3.04$ per PHEV) while the electric driving range surprisingly increases by $37.5 \%$, from 16 to 22 miles. This suggests that a larger battery would allow drivers to better utilize the workplace chargers to achieve longer electrified distances and save more regarding their operating costs. Consequently, the social cost is reduced with a larger battery if those who will benefit the most from charging will get the opportunity to recharge. When one charger is available for every 3.66 vehicles, with a 22-mile battery for the trip from work to home, 19.94 miles per charger are electrified on average compared to 14.97 miles per charger that would be electrified if the battery was still a 16-mile one. With a 22-mile battery, the additional average electrified miles per $\mathrm{kWh}$ due to charging is 0.33 , while a 16-mile one yields only 0.30 miles per $\mathrm{kWh}$. In other words, the value per unit of battery capacity increases. We conclude that it is in the interest of the society to deploy workplace chargers to further reduce the social cost of driving. 

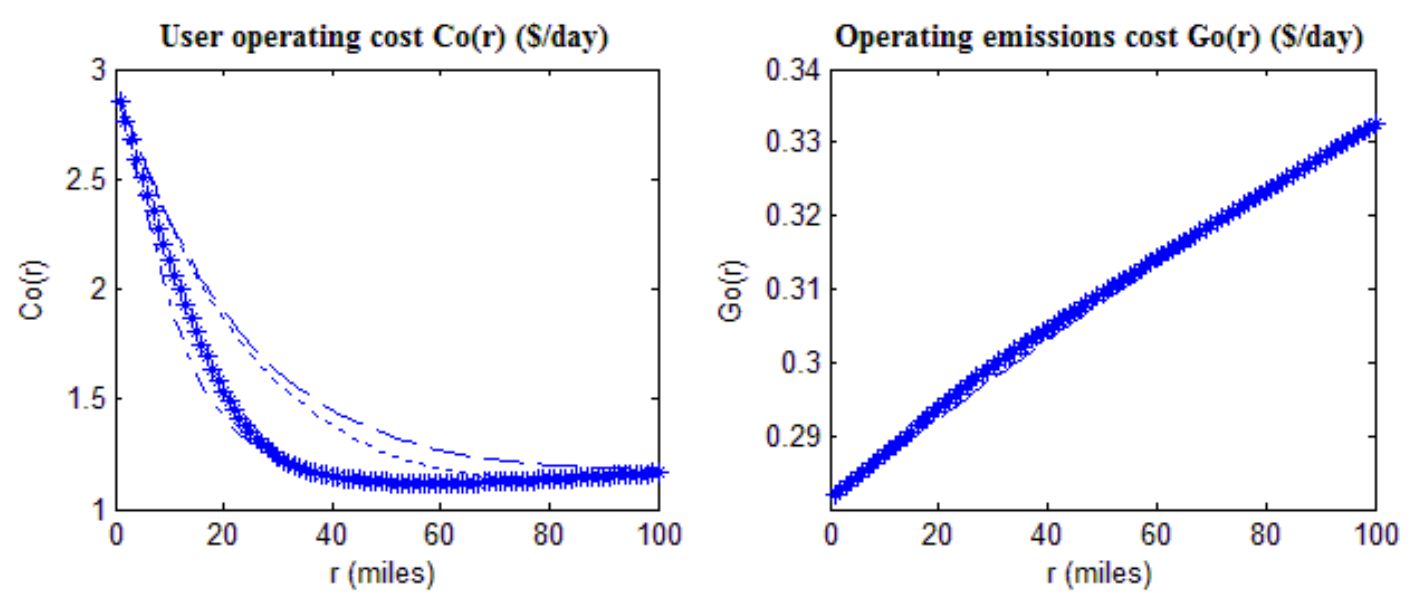

Total Cost C(r) (\$/day)

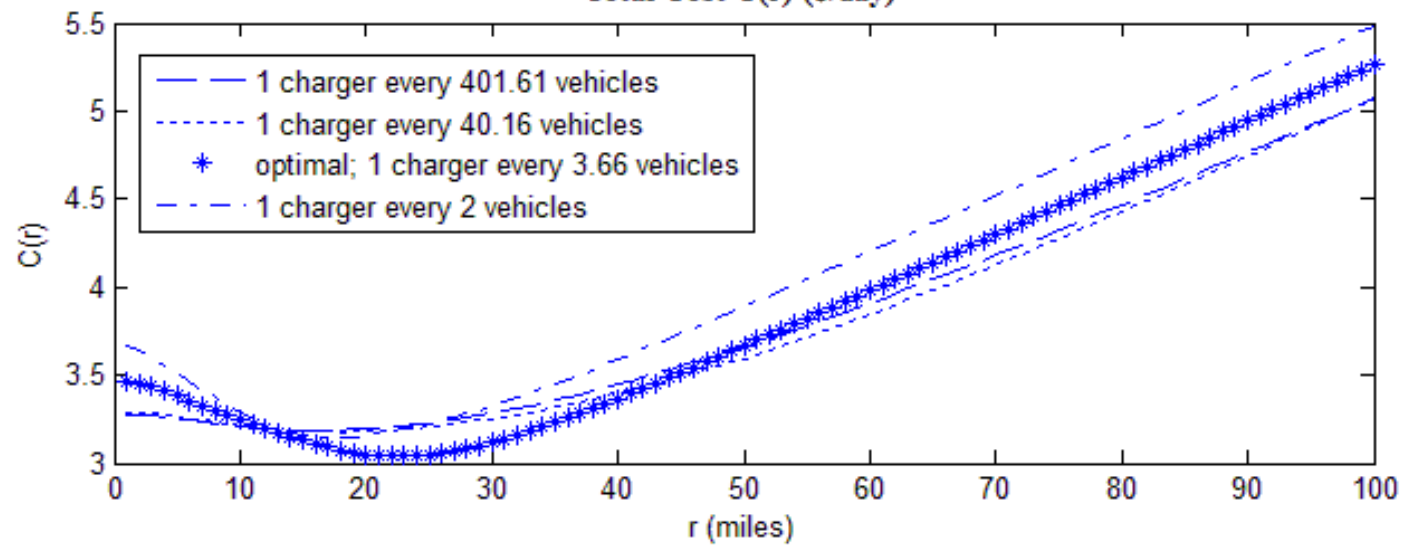

Fig. 5. Average societal cost with work-charging availability

\subsection{Diversification of electric driving range}

In this extension, we investigate the effects of introducing two or three different electric driving ranges of PHEVs. PHEVs' batteries could become diversified in the market in order to appeal to more market segments (Lin, 2014). Here we examine optimal pair and triple of electric driving ranges to further reduce the societal cost. With more than one driving range available, each PHEV user is assumed to select the one that minimizes exclusively their internal user cost (battery and operating cost). Therefore, the problem once again possesses a leader-followers game structure and can be formulated as the following bi-level programming model (using the case of triple battery sizes as an example):

$$
\begin{aligned}
\min C\left(r_{1}, r_{2}, r_{3}, z_{j}\right) & \\
& =\sum_{j}\left(\left(C_{u_{j}}\left(r_{1}\right)+C_{e_{j}}\left(r_{1}\right)\right) \cdot z_{j 1}^{*}+\left(C_{u_{j}}\left(r_{2}\right)+C_{e_{j}}\left(r_{2}\right)\right) \cdot z_{j 2}^{*}\right. \\
& \left.+\left(C_{u_{j}}\left(r_{3}\right)+C_{e_{j}}\left(r_{3}\right)\right) \cdot z_{j 3}^{*}\right) \\
\text { s.t. } & 0 \leq r_{1}, r_{2}, r_{3} \leq r_{u}
\end{aligned}
$$


$z_{j}^{*}=\operatorname{argmin}\left\{C_{u_{j}}\left(r_{1}\right) z_{j 1}+C_{u_{j}}\left(r_{2}\right) z_{j 2}+C_{u_{j}}\left(r_{3}\right) z_{j 3} \mid z_{j 1}+z_{j 2}+z_{j 3}=1, z_{j} \in\{0,1\}\right\}, \forall j$

where $r_{1}, r_{2}, r_{3}$ are the triple of electric driving ranges in miles; $z_{j 1}, z_{j 2}, z_{j 3}$ are the binary variables denoting which driving range is selected by user $j$, based on the minimization of his or her own user cost and $z_{j}=\left\{z_{j 1}, z_{j 2}, z_{j 3}\right\}^{T}$. In the above, the upper-level problem describes the decision of introducing three driving ranges while the lower-level problem describe the decision of each user on which driving range to use. Clearly, $z_{j 1}+z_{j 2}+z_{j 3}=1$ ensures that each user can choose exactly one driving range to minimize his or her internal cost. For this extension, charging is exclusively considered home based.

The results indicate that the optimal driving range pair is 8 and 40 miles and the optimal triple is7, 24 and 51 miles respectively. The daily social cost is $\$ 2.95$ per PHEV and $\$ 2.82$ per PHEV, a reduction of $7.45 \%$ and $11.5 \%$ respectively, as compared to the case of a single driving range. As expected, the diversification of the battery size can decrease substantially the social cost (as well as the individual user cost).

It is interesting to note that diversifying electric driving ranges appears more effective than deploying workplace chargers on reducing the social costs. The policy allows drivers with various VMTs to select the range to better suit their needs. Specifically, in the case of offering two driving ranges, $63.14 \%$ of drivers choose the 8 -mile range while the rest chooses the range of 40 miles. For the case of triple ranges, $44.82 \%, 33.17 \%$ and $22.01 \%$ of drivers choose the range of 7, 24 and 51 miles respectively.

\section{Conclusions}

The PHEV technology diversifies the choice of energy for powering personal transportation and, at the same time, has the potential for achieving higher energy efficiency and decreasing environmental impacts. In order to achieve the maximum benefit for society when using this vehicle technology, we have developed an optimization framework to determine an optimal driving range to minimize the societal cost. We further enhanced the optimization framework to be a bi-level programing framework to (1) optimize the deployment of workplace charging infrastructure and examine its impacts on the social cost and battery size; and (2) determine the optimal diversification of electric driving ranges. We demonstrated the modeling frameworks using empirical data from the U.S. automobile and travel markets. Results indicate that the optimal driving range to achieve the minimum social cost is 16 miles. The optimal value of the electric driving range is found to be sensitive to factors such as the battery pack cost and gasoline price. The results suggest that it is in the interest of the society to adopt certain policies to encourage car manufactures to produce PHEVs with a lower driving range, compared to those available in the market. When considering optimal deployment of workplace chargers, the optimal electric driving range surprisingly increases to 22 miles. With a charger every 3.66 vehicles, the daily social cost drops by approximately $4.54 \%$. Lastly, the introduction of two or three PHEV electric driving range options can lead to a reduction of $7.45 \%$ and $11.5 \%$ respectively of the cost borne by the society.

\section{ACKNOWLEDGEMENTS}


The work described in this paper was partly supported by the U.S. National Science Foundation (CNS-1239364) and National Natural Science Foundation of China (71228101). We would also like to thank the support from Lloyd's Register Foundation (LRF). LRF helps to protect life and property by supporting engineering-related education, public engagement and the application of research. The authors would like to thank three anonymous reviewers for their comments and suggestions.

\section{REFERENCES}

Delucchi, M. a. (2000). Environmental externalities of motor vehicle use in the US. Journal of Transport and Policy. Retrieved from http://www.bath.ac.uk/ejournals/jtep/pdf/Volume_34_Part_2_135-168.pdf

Department of Energy, U. S. (2014a). Alternative Fuel Transportation Program; Alternative Fueled Vehicle Credit Program Modification and Other Amendments. Federal Register. Retrieved from https://www.federalregister.gov/articles/2001/04/25/01-10237/minimumdriving-range-for-dual-fueled-electric-passenger-automobiles\#h-6

Department of Energy, U. S. (2014b). www.fueleconomy.gov, the official U.S. government source for fuel economy information. Retrieved from www.fueleconomy.gov/feg/phevsbs.html

Dong, J., \& Lin, Z. (2012). Within-day recharge of plug-in hybrid electric vehicles: Energy impact of public charging infrastructure. Transportation Research Part D: Transport and Environment, 17(5), 405-412. http://doi.org/http://dx.doi.org/10.1016/j.trd.2012.04.003

Elgowainy, A., Burnham, A., Wang, M., Molburg, J., \& Rousseau, A. (2009). Well-to-wheels energy use and greenhouse gas emissions of plug-in hybrid electric vehicles. $S A E$ International Journal of Fuels and Lubricants, 2(1), 627.

Energy Information Administration. (2013). Annual projection to 2040 (Early Release): A7. Transportation Sector Jey Indicators and Delivered Energy Consumption. U.S. Department of Energy. Retrieved from http://www.eia.gov/oiaf/aeo/tablebrowser/\#release=AEO2014ER\&subject=0AEO2014ER\&table=7-AEO2014ER\&region=0-0\&cases=full2013-d102312a,ref2014erd102413a

Environmental Protection Agency, U. S. (2013). Social Cost of Carbon. Climate Change. Retrieved from http://www.epa.gov/climatechange/EPAactivities/economics/scc.html

Ernst, C.-S., Hackbarth, A., Madlener, R., Lunz, B., Uwe Sauer, D., \& Eckstein, L. (2011). Battery sizing for serial plug-in hybrid electric vehicles: A model-based economic analysis for Germany. Energy Policy, 39(10), 5871-5882. http://doi.org/http://dx.doi.org/10.1016/j.enpol.2011.06.038

He, F., Wu, D., Yin, Y., \& Guan, Y. (2013). Optimal deployment of public charging stations for plug-in hybrid electric vehicles. Transportation Research Part B: Methodological, 47(0), 87-101. http://doi.org/http://dx.doi.org/10.1016/j.trb.2012.09.007

Lin, Z. (2012). Optimizing and Diversifying the Electric Range of Plug-in Hybrid Electric Vehicles for U.S. Drivers. SAE International Journal of Alternative Powertrains, 1(1), 180 194. 
Lin, Z. (2014). Optimizing and Diversifying Electric Vehicle Driving Range for U.S. Drivers. Transportation Science, 48(4), 635-650. http://doi.org/10.1287/trsc.2013.0516

Lipman, T. E., \& Delucchi, M. a. (2006). A retail and lifecycle cost analysis of hybrid electric vehicles. Transportation Research Part D: Transport and Environment, 11, 115-132. http://doi.org/10.1016/j.trd.2005.10.002

Markel, T., Tataria, H. S., \& Howell, D. (2009). Battery Requirements for Plug-in Hybrid Electric Vehicles--analysis and Rationale. National Renewable Energy Laboratory.

Michalek, J. J., Chester, M., Jaramillo, P., Samaras, C., Shiau, C.-S. N., \& Lave, L. B. (2011). Valuation of plug-in vehicle life-cycle air emissions and oil displacement benefits.

Proceedings of the National Academy of Sciences, 108(40), 16554-16558. http://doi.org/10.1073/pnas.1104473108

National Research Council Committee on Assessment of Resource Needs for Fuel, C., \& Hydrogen, T. (2010). Transitions to alternative transportation technologies plug-in hybrid electric vehicles. Washington, D.C: National Academies Press. Retrieved from http://uh7qf6fd4h.search.serialssolutions.com/?V=1.0\&L=UH7QF6FD4H\&S=JCs\&C=TC0 $000430008 \& \mathrm{~T}=$ marc $\&$ tab $=$ BOOKS

Neubauer, J., \& Pesaran, A. (2011). The ability of battery second use strategies to impact plug-in electric vehicle prices and serve utility energy storage applications. Journal of Power Sources, 196(23), 10351-10358.

Norman Shiau, C.-S., \& Michalek, J. J. (2011). Global Optimization of Plug-In Hybrid Vehicle Design and Allocation to Minimize Life Cycle Greenhouse Gas Emissions. Journal of Mechanical Design, 133(8), 084502. http://doi.org/10.1115/1.4004538

Parry, M. L. (2007). Climate Change 2007: impacts, adaptation and vulnerability: contribution of Working Group II to the fourth assessment report of the Intergovernmental Panel on Climate Change (Vol. 4). Cambridge University Press.

Pearre, N. S., Kempton, W., Guensler, R. L., \& Elango, V. V. (2011). Electric vehicles: How much range is required for a day's driving? Transportation Research Part C: Emerging Technologies, 19(6), 1171-1184. http://doi.org/http://dx.doi.org/10.1016/j.trc.2010.12.010

Pesaran, A., Markel, T., Tataria, H. S., \& Howell, D. (2007). Battery Requirements for Plug-In Hybrid Electric Vehicles: Analysis and Rationale. In 23rd International Electric Vehicle Symposium and Exposition (EVS-23). Anaheim, CA.

Peterson, S. B., \& Michalek, J. J. (2013). Cost-effectiveness of plug-in hybrid electric vehicle battery capacity and charging infrastructure investment for reducing US gasoline consumption. Energy Policy, 52(0), 429-438. http://doi.org/http://dx.doi.org/10.1016/j.enpol.2012.09.059

Rosenthal, R. E. (2015). GAMS - A User' s Guide, (April).

Samaras, C., \& Meisterling, K. (2008). Life cycle assessment of greenhouse gas emissions from plug-in hybrid vehicles: implications for policy. Environmental Science \& Technology, 42(9), 3170-3176.

Shiau, C.-S. N., Kaushal, N., Hendrickson, C. T., Peterson, S. B., Whitacre, J. F., \& Michalek, J. J. (2010). Optimal Plug-In Hybrid Electric Vehicle Design and Allocation for Minimum Life Cycle Cost, Petroleum Consumption, and Greenhouse Gas Emissions. Journal of Mechanical Design, 132(9), 091013. http://doi.org/10.1115/1.4002194

Shiau, C.-S. N., \& Michalek, J. J. (2011). Global Optimization of Plug-In Hybrid Vehicle Design and Allocation to Minimize Life Cycle Greenhouse Gas Emissions. Journal of Mechanical Design, 133(8), 084502. http://doi.org/10.1115/1.4004538 
Shiau, C.-S. N., Samaras, C., Hauffe, R., \& Michalek, J. J. (2009). Impact of battery weight and charging patterns on the economic and environmental benefits of plug-in hybrid vehicles. Energy Policy, 37(7), 2653-2663. http://doi.org/http://dx.doi.org/10.1016/j.enpol.2009.02.040

Smith, R., Shahidinejad, S., Blair, D., \& Bibeau, E. L. (2011). Characterization of urban commuter driving profiles to optimize battery size in light-duty plug-in electric vehicles. Transportation Research Part D: Transport and Environment, 16(3), 218-224. http://doi.org/http://dx.doi.org/10.1016/j.trd.2010.09.001

Stephens, T. (2013). Non-Cost Barriers to Consumer Adoption of New Light-Duty Vehicle Technologies. Transportation Energy Futures Series.

Tessum, C. W., Hill, J. D., \& Marshall, J. D. (2014). Life Cycle Air Quality Impacts of Conventional and Alternative Light-Duty Transportation in the United States. Proceedings of the National Academy of Sciences, 111(52), 18490-18495. http://doi.org/10.1073/pnas.1406853111

Traut, E., Hendrickson, C., Klampfl, E., Liu, Y., Michalek, J. J., \& Hall, S. (2011). Optimal design and allocation of electrified vehicles and dedicated charging infrastructure for minimum greenhouse gas emissions. In TRB Annual Meeting.

Traut, E. J., Cherng, T. C., Hendrickson, C., \& Michalek, J. J. (2013). US residential charging potential for electric vehicles. Transportation Research Part D: Transport and Environment, 25(0), 139-145. http://doi.org/http://dx.doi.org/10.1016/j.trd.2013.10.001

U.S. Department of Transportation. Federal Highway Administration. (2009). 2009 National Household Travel Survey. Retrieved from http://nhts.ornl.gov/

Waltz, R., \& Plantenga, T. (2009). Knitro User's Manual Version 6.0.

Yilmaz, M., \& Krein, P. T. (2013). Review of Battery Charger Topologies, Charging Power Levels, and Infrastructure for Plug-In Electric and Hybrid Vehicles. Power Electronics, IEEE Transactions on, 28(5), 2151-2169. http://doi.org/10.1109/TPEL.2012.2212917

Zhang, L., Brown, T., \& Samuelsen, G. S. (2011). Fuel reduction and electricity consumption impact of different charging scenarios for plug-in hybrid electric vehicles. Journal of Power Sources, 196(15), 6559-6566. http://doi.org/http://dx.doi.org/10.1016/j.jpowsour.2011.03.003 